\title{
Montelukast as an alternative to low-dose inhaled corticosteroids in the management of mild asthma (the SIMPLE trial): An open-label effectiveness trial
}

\author{
R Andrew Mclvor $\mathrm{MD}^{1}$, Alan Kaplan $\mathrm{MD}^{2}$, Caroline Koch $\mathrm{PhD}^{3}$, John S Sampalis $\mathrm{PhD}^{4,5}$
}

\begin{abstract}
RA McIvor, A Kaplan, C Koch, JS Sampalis. Montelukast as an alternative to low-dose inhaled corticosteroids in the management of mild asthma (the SIMPLE trial): An open-label effectiveness trial. Can Respir J 2009;16(Suppl A):11A-16A.
\end{abstract}

OBJECTIVE: To evaluate the effectiveness of montelukast as monotherapy for patients with mild asthma who remain uncontrolled or unsatisfied while on inhaled corticosteroid (ICS) monotherapy.

DESIGN: A multicentre, open-label study. Patients (six years of age or older) had ICS therapy discontinued and were treated with orally administered montelukast once daily for six weeks.

MAIN OUTCOME MEASURES: The primary outcome measure was the rate at which asthma symptom control was achieved or maintained after six weeks of treatment. The secondary outcome measures were to compare compliance and physician satisfaction, and to further assess the safety and tolerability of montelukast.

RESULTS: Of the 534 patients enrolled, 481 (90.1\%) completed the study. Mean $( \pm$ SD) age was $27.8 \pm 19.0$ years. The number of patients with uncontrolled symptoms decreased from $455(85.2 \%)$ at baseline to 143 $(26.8 \%)$ at week $6(\mathrm{P}<0.001)$, and mean Asthma Control Questionnaire score decreased from $1.4 \pm 0.8$ to $0.6 \pm 0.6(\mathrm{P}<0.001)$, representing a clinically significant improvement. Of the 79 patients with controlled asthma symptoms at baseline, $73.4 \%$ maintained asthma control at week 6 . Compliance to asthma therapy increased from $41 \%$ at baseline for ICS to $88 \%$ at week 6 for montelukast $(\mathrm{P}<0.001)$. Physician satisfaction with treatment increased from $43 \%$ to $85 \%(\mathrm{P}<0.001)$ and patient satisfaction increased from $45 \%$ at baseline to $94 \%$ at week 6 . No serious adverse events were reported over the course of the study.

CONCLUSION: Montelukast is an effective and well-tolerated alternative to ICS treatment in patients with mild asthma who are uncontrolled or unsatisfied with low-dose ICS therapy.

Key Words: Adherence; Allergic rhinitis; Asthma; Inhaled corticosteroids (ICS); Montelukast

$\mathrm{T}$ he incidence and prevalence of asthma is increasing and is associated with rhinitis as a common comorbidity (1-4). Patients with both asthma and allergic rhinitis (AR) are known to have higher rates of exacerbations and associated health care burden $(5,6)$. Effective control of asthma symptoms in this population is therefore of high priority.

Current guidelines call for orally inhaled low-dose inhaled corticosteroids (ICS) as first-line treatment for mild to moderate asthma $(1,7,8)$. However, there is a significant number of patients that remain uncontrolled despite treatment. This treatment gap is most likely due a number of factors, including poor compliance or adherence, smoking and associated comorbidities (eg, AR, gastroesophageal reflux and obesity) (9-22).

Montelukast is a leukotriene receptor antagonist that has been shown to be effective as monotherapy or as an add-on to other treatments for asthma patients who are not controlled with ICS

\section{Le montélukast en remplacement des}

corticostéroïdes en inhalation à faible dose pour le traitement de l'asthme léger (étude SIMPLE) : essai sur l'efficacité mené au su

OBJECTIF : Évaluer l'efficacité du montélukast en monothérapie chez des patients qui souffrent d'asthme léger non maitrisé au moyen d'une monothérapie avec un corticostéroïde en inhalation (CSI) ou qui sont insatisfaits de ce traitement.

PROTOCOLE : Étude multicentrique ouverte. Les patients (âgés de 6 ans et plus) ont cessé leur traitement et ont reçu du montélukast administré par voie orale une fois par jour pendant six semaines.

PARAMÈTRES D’ÉVALUATION : Le paramètre principal était de vérifier la proportion de patients ayant réussi à maîtriser les symptômes de l'asthme ou à maintenir la maîtrise des symptômes de l'asthme après six semaines de traitement. Les paramètres secondaires portaient sur l'observance du traitement et la satisfaction du médecin au début et à la fin de l'étude ainsi que sur l'innocuité et le profil de tolérance du montélukast.

RÉSULTATS : Des 534 patients admis à l'étude, 481 (90,1\%) ont terminé l'étude. L'âge moyen ( \pm É.T.) était de 27,8 \pm 19,0 ans. Le nombre de patients dont les symptômes n'étaient pas maîtrisés est passé de 455 $(85,2 \%)$ au départ à $143(26,8 \%)$ à la semaine $6(\mathrm{p}<0,001)$, et l'indice moyen au questionnaire de la maîtrise de l'asthme (indice ACQ), de $1,4 \pm 0,8$ à $0,6 \pm 0,6(\mathrm{p}<0,001)$, ce qui représente une amélioration significative sur le plan clinique. Chez les 79 patients dont l'asthme était maîtrisé au départ, 73,4 \% conservaient toujours la maitrise de leurs symptômes à la semaine 6 . L'observance du traitement antiasthmatique est passée de $41 \%$ au départ avec le CSI à $88 \%$ à la semaine 6 avec le montélukast $(\mathrm{p}<0,001)$. La satisfaction des médecins à l'égard du traitement est passée de $43 \%$ au départ à $85 \%$ à la semaine $6(\mathrm{p}<0,001)$ et celle des patients, de $45 \%$ à $94 \%$. Aucun effet indésirable grave n'a été rapporté au cours de l'étude.

CONCLUSION : Le montélukast est un traitement de rechange efficace et bien toléré pour les patients qui souffrent d'asthme léger non maîtrisé avec une monothérapie au moyen d'un corticostéroïde en inhalation (CSI) à faible dose ou qui sont insatisfaits de ce traitement.

therapy (1,8,23-26). The primary purpose of the SIngulair in Mild asthma: comPLiance and Effectiveness (SIMPLE) study was to assess the effectiveness of montelukast in managing patients with mild asthma who were either not controlled or not satisfied with ICS treatment. A subgroup analysis was performed on patients having concurrent AR. Secondary objectives of the study were to compare compliance and patient and physician satisfaction with low-dose ICS treatment versus montelukast treatment; to estimate the proportion of patients with uncontrolled asthma while on lowdose ICS; and to further assess the safety and tolerability of montelukast in patients with mild asthma.

Study design

METHODS

This was a multicentre, Canadian, phase IV study with two phases: a survey phase and a treatment phase. In the survey phase of the

${ }^{1}$ Firestone Institute of Respiratory Health, McMaster University, Hamilton; ${ }^{2}$ York Central Hospital, Richmond Hill, Ontario; ${ }^{3}$ Merck Frosst

Canada Limited, Kirkland; ${ }^{4}$ JSS Medical Research Inc, Montreal; ${ }^{5}$ Faculty of Medicine, McGill University, Montreal, Quebec

Correspondence: Dr Andrew McIvor, McMaster University, St Joseph's Healthcare, Firestone Institute for Respiratory Health, T2127,

50 Charlton Ave E, Hamilton, Ontario L8N 4A6. Telephone 905-522-1155 ext 34330, fax 905-521-6183, e-mail amcivor@stjosham.on.ca 
TABLE 1

Demographic and baseline characteristics

\begin{tabular}{lccc}
\hline & & \multicolumn{2}{c}{ Treatment phase } \\
\cline { 3 - 4 } Baseline characteristics & $\begin{array}{c}\text { Survey phase } \\
(\mathbf{n}=\mathbf{1 8 1 7})\end{array}$ & $\begin{array}{c}\text { All patients } \\
(\mathbf{n}=534)\end{array}$ & $\begin{array}{c}\text { Concurrent } \\
\text { AR }(\mathbf{n}=\mathbf{3 0 5})\end{array}$ \\
\hline Age, years & $31.9 \pm 20.5$ & $27.8 \pm 19.0$ & $28.4 \pm 17.6$ \\
Age categories, $\mathrm{n}(\%)$ & & & \\
$\quad$ 6-14 years & $577(31.8)$ & $213(39.9)$ & $105(34.4)$ \\
$\geq 15$ years & $1240(68.2)$ & $321(60.1)$ & $200(65.6)$ \\
Sex, $\mathrm{n}(\%)$ & & & \\
$\quad$ Male & $779(42.9)$ & $233(43.6)$ & $134(43.9)$ \\
$\quad$ Female & $1038(57.1)$ & $301(56.4)$ & $171(56.1)$ \\
Duration of mild asthma & $95.0 \pm 102.0$ & $83.5 \pm 92.8$ & $82.6 \pm 88.6$ \\
$\quad$ diagnosis, months & & & \\
Specialty of treating physician, $\mathrm{n}(\%)$ & & \\
$\quad$ General/family practitioner & $\mathrm{NA}$ & $390(73.0)$ & $230(75.4)$ \\
$\quad \begin{array}{l}\text { Pediatrician } \\
\text { Allergist }\end{array}$ & $\mathrm{NA}$ & $128(24.0)$ & $62(20.3)$ \\
\hline
\end{tabular}

Data presented as mean $\pm S D$ unless otherwise specified. AR Allergic rhinitis; NA Not available

study, investigators were asked to enroll consecutive patients with mild asthma who were currently treated with low-dose ICS monotherapy. The aim of the survey was to estimate the proportion of patients who had uncontrolled symptoms or who were dissatisfied with their current ICS treatment.

Among the patients who were enrolled in the survey, those who had uncontrolled symptoms, or were dissatisfied or nonadherent to their low-dose ICS therapy, were invited to participate in the treatment phase of the study.

The treatment phase was a six-week, prospective cohort, openlabel study. Eligible patients who agreed to participate in the treatment phase had their ICS treatment interrupted and were treated with montelukast monotherapy for six weeks. Clinical assessments were conducted at baseline (week 0) and at six weeks. All patients gave written informed consent before their participation in the study. Before each visit, all patients were asked to refrain from the use of their short-acting beta-2-agonist for $6 \mathrm{~h}$.

The study was approved by two independent ethics review boards (IRB Services, Aurora, Ontario, and the College of Physicians and Surgeons of Alberta, Edmonton, Alberta).

\section{Subject selection criteria}

For the survey phase of the study, eligible patients were six years of age or older, diagnosed with mild, persistent asthma and treated with a low-dose ICS ( $250 \mu \mathrm{g} /$ day or less of fluticasone or equivalent). Mild asthma was assessed by the treating physician and was described in the protocol as suffering from recurrent but not daily asthma symptoms, and having exacerbations that may be affecting the patient's activities and sleep. In addition to the above criteria, patients eligible for the treatment phase of the study had to fulfill the following additional inclusion criteria: completion of the survey phase; treated with their low-dose ICS for a minimum of six weeks before study initiation; forced expiratory volume in $1 \mathrm{~s}$ of $80 \%$ or greater of the predicted value; and fulfill at least one of the following criteria: uncontrolled asthma symptoms, dissatisfaction with current low-dose ICS, or unwilling to use low-dose ICS therapy. For the purposes of the present study, uncontrolled asthma was defined as the presence of at least one of the parameters of uncontrolled asthma, based on the current Canadian Asthma Consensus guidelines at the time of the study (27).

Patients were excluded if they were currently treated with montelukast or any of the following: moderate- to high-dose ICS (greater than $250 \mu \mathrm{g} /$ day fluticasone or equivalent), a long-acting beta-2-agonist, combination therapy of an ICS with a long-acting beta-2-agonist, prednisone, regular use of theophylline or other asthma medications such as sodium cromoglycate or nedocromil. They were also excluded if they had a history of hypersensitivity to any component of montelukast. Demographic and baseline characteristics are outlined in Table 1.

\section{Treatment}

ICS treatment was discontinued at the enrolment visit of the treatment phase of the study. During the treatment phase, patients who were 15 years of age or older were treated with $10 \mathrm{mg}$ montelukast sodium (Singulair, Merck \& Co Inc. USA) tablets taken once daily at bedtime. Patients who were between six and 14 years of age were treated with $5 \mathrm{mg}$ montelukast sodium tablets taken once daily at bedtime. A short-acting beta-2-agonist as rescue medication was allowed during the study.

\section{Outcome measures}

The primary effectiveness outcome measure was the proportion of patients in whom asthma symptom control was achieved or maintained after six weeks of treatment with montelukast. Control of asthma symptoms was defined as the absence of all symptoms of asthma, as outlined in the Canadian Asthma Consensus guidelines (Table 2) (27). A secondary measure of effectiveness was the absolute change in the Asthma Control Questionnaire (ACQ) score between the baseline and the six-week assessment. The ACQ is self-administered and consists of seven seven-point Likert scale questions that describe the frequency and severity of asthma symptoms (28). The ACQ score is calculated as the mean of the seven items. The ACQ score ranges between 0 (well-controlled) and 6 (extremely poorly controlled); a score of 1.5 or greater indicates uncontrolled symptoms (29) and a change of 0.5 or greater is considered to be clinically important (28). Physician and patient satisfaction with treatment were assessed at baseline and at week 6 with a five-point Likert scale question which ranged from 0 (very dissatisfied) to 4 (very satisfied). Compliance with ICS treatment was assessed at baseline, and compliance with montelukast treatment was assessed at week 6 by the treating physician. Compliance was measured with a dichotomous question asking whether the patient missed any asthma medication doses and with a quantitative question that ascertained the number of times the patient did not take the asthma medication. Noncompliance was defined as taking less than $80 \%$ of the required asthma medication doses.

\section{Statistical methods}

The statistical significance of the respective changes in asthma control, treatment satisfaction and treatment adherence from baseline to week 6 was assessed with the McNemar-Bowker test for paired dichotomous data. The statistical significance of the mean change in ACQ score was assessed with Student's $t$ test for paired samples. Safety was assessed by the incidence of treatment-related adverse events, which were coded and reported according to the Medical Dictionary for Regulatory Activities Terminology dictionary of terms, version 9.0 (30). Sample size requirements for the treatment phase were established as the minimum required for a precision of $\pm 5 \%$ in the estimate of the primary outcome measure - specifically, control of asthma symptoms at six weeks. For these requirements, a sample size of approximately 500 patients was established to provide a $95 \% \mathrm{CI}$ of $\pm 5 \%$.

The above analyses were conducted for the sample as a whole and for the subgroup of patients diagnosed with both asthma and AR. There were no imputations for missing data. As per the reallife aim of the study, the intent-to-treat principle was applied for the analysis of effectiveness. Therefore, all patients, including those with protocol violations, were included in the effectiveness 


\begin{tabular}{|c|c|c|c|c|c|c|}
\hline & \multicolumn{3}{|c|}{ All patients } & \multicolumn{3}{|c|}{ Concurrent AR patients } \\
\hline & $\begin{array}{l}\text { Baseline with } \\
\text { ICS treatment, } \\
\qquad n=534\end{array}$ & $\begin{array}{c}\text { Week } 6 \text { with } \\
\text { MON treatment, } \\
n=481\end{array}$ & $\mathbf{P}^{*}$ & $\begin{array}{l}\text { Baseline with } \\
\text { ICS treatment, } \\
\qquad n=305\end{array}$ & $\begin{array}{c}\text { Week } 6 \text { with } \\
\text { MON treatment, } \\
n=274\end{array}$ & $\mathbf{P}^{*}$ \\
\hline \multicolumn{7}{|l|}{ Presence of at least one of the following, $\mathrm{n}(\%)$} \\
\hline Daytime symptoms $\geq 4$ days/week & $302(56.6)$ & $58(12.1)$ & $<0.001$ & $179(58.7)$ & $36(13.1)$ & $<0.001$ \\
\hline Night-time symptoms $\geq 1$ night/week & $278(52.1)$ & $56(11.6)$ & $<0.001$ & $170(55.7)$ & $36(13.1)$ & $<0.001$ \\
\hline Physical activity restricted in the past 6 weeks & $256(47.9)$ & $38(7.9)$ & $<0.001$ & $154(50.5)$ & $21(7.7)$ & $<0.001$ \\
\hline Any exacerbation in the past 6 weeks & $276(51.7)$ & $49(10.2)$ & $<0.001$ & $166(54.4)$ & $28(10.2)$ & $<0.001$ \\
\hline Missed school/work due to asthma symptoms in the past 6 weeks & $97(18.2)$ & $10(2.1)$ & $<0.001$ & $59(19.3)$ & $6(2.2)$ & $<0.001$ \\
\hline Short-acting beta-2-agonist $>3$ doses/week and $<7$ doses/week ${ }^{\dagger}$ & $244(45.7)$ & $60(12.5)$ & $<0.001$ & $145(47.5)$ & $33(12.0)$ & $<0.001$ \\
\hline
\end{tabular}

${ }^{*}$ Based on McNemar-Bowker Test; ${ }^{\dagger}$ Excluding preventive use for exercise-induced symptoms. AR Allergic rhinitis; ICS Inhaled corticosteroid; MON Montelukast

TABLE 3

Outcome assessment at week 6

\begin{tabular}{|c|c|c|c|c|c|c|c|c|}
\hline \multirow[b]{2}{*}{ Asthma symptoms, n (\%) } & \multicolumn{4}{|c|}{ All patients } & \multicolumn{4}{|c|}{ Concurrent AR patients } \\
\hline & $\begin{array}{c}\text { Controlled at } \\
\text { baseline*, n=79 }\end{array}$ & $\begin{array}{c}\text { Uncontrolled at } \\
\text { baseline }^{\dagger}, \mathrm{n}=455\end{array}$ & $\begin{array}{l}\text { Total, } \\
n=534\end{array}$ & $\mathbf{P}^{\ddagger}$ & $\begin{array}{c}\text { Controlled at } \\
\text { baseline*, n=38 }\end{array}$ & $\begin{array}{l}\text { Uncontrolled at } \\
\text { baseline, } n=267\end{array}$ & $\begin{array}{l}\text { Total, } \\
n=305\end{array}$ & $\mathbf{P}^{\ddagger}$ \\
\hline Controlled & $58(73.4)$ & $249(54.7)$ & 307 (57.5) & $<0.001$ & $30(78.9)$ & $142(53.2)$ & $172(56.4)$ & $<0.001$ \\
\hline Uncontrolled & $12(15.2)$ & $131(28.8)$ & $143(26.8)$ & & $4(10.5)$ & $81(30.3)$ & 85 (27.9) & \\
\hline Discontinued & $5(6.3)$ & $48(10.5)$ & $53(9.9)$ & & $4(10.5)$ & $27(10.1)$ & $31(10.2)$ & \\
\hline Missing data & $4(5.1)$ & $27(5.9)$ & $31(5.8)$ & & $0(0.0)$ & $17(6.4)$ & $17(5.6)$ & \\
\hline
\end{tabular}

${ }^{*}$ Not satisfied or noncompliant with inhaled corticosteroid therapy at baseline; ${ }^{\dagger}$ Patients that had controlled symptoms but were dissatisfied or noncompliant with the inhaled corticosteroid treatment; ${ }^{\ddagger}$ Based on the McNemar-Bowker test. AR Allergic rhinitis

analysis provided six-week data were available. All patients who received at least one dose of the study medication were included in the safety analysis. The analyses were performed using SPSS version 12.0 for Windows (SPSS Inc, USA).

\section{Patient disposition}

\section{RESULTS}

Patient enrolment began in September 2004; the last patient was enrolled in October 2005 and the last follow-up visit was completed in December 2005. In total, 1817 patients were screened by 113 physician-investigators and were included in the survey phase of the study. Of these, 534 eligible patients (29.4\%) from 85 sites $(75.2 \%)$ agreed to participate in the treatment phase of the study. Of the 534 enrolled patients, 481 (90.1\%) completed the six-week assessment. During the treatment phase, 53 patients (9.9\%) discontinued before the six-week follow-up visit: 28 (5.2\%) were lost to follow-up, eight $(1.5 \%)$ withdrew due to an adverse event, 13 $(2.4 \%)$ were protocol violations, three $(0.6 \%)$ were noncompliant and one $(0.2 \%)$ patient withdrew for other reasons. These 53 patients were not included in the effectiveness analysis because six-week data were not available.

\section{Survey phase}

The demographics and characteristics of the 1817 patients who completed the survey phase of the study are described in Table 1. There were 1397 patients (76.9\%) with uncontrolled asthma symptoms, 1379 patients $(75.9 \%)$ who were nonadherent with their ICS regimen, and 439 patients $(24.2 \%)$ who reported that they were dissatisfied or very dissatisfied with their ICS treatment.

\section{Treatment phase}

Of the 534 patients enrolled in the treatment phase of the study, $305(57.1 \%)$ were diagnosed with concurrent AR by the treating physician based on their medical history or a symptom review. Among these patients, 455 (85\%) had uncontrolled symptoms at baseline and 79 (15\%) had controlled symptoms but were dissatisfied or noncompliant with the ICS monotherapy. Demographic data and baseline characteristics for these two groups are described in Table 1 . The majority of patients $(n=375$ $70.2 \%$ ) were taking fluticasone as their low-dose ICS at baseline, followed by budesonide ( $n=77 ; 14.5 \%)$.

Table 2 describes the asthma symptom profiles at the baseline and six-week assessments for all patients and for those with concurrent AR based on the Canadian Asthma Consensus guidelines. At baseline, the most commonly reported symptom was 'daytime symptoms $\geq 4$ days/week'. A similar baseline symptom profile was observed for the 305 patients with concurrent AR. For all six asthma symptom criteria, the changes in responses from the baseline to six-week assessments were statistically significant (all $\mathrm{P}<0.001$ ) (Table 2).

At the baseline assessment, 455 patients (85.2\%) had uncontrolled asthma symptoms, and 79 (14.8\%) had controlled asthma symptoms but were not satisfied with or were reluctant to use their current ICS treatment (Table 3). Of the 79 patients with controlled asthma symptoms at baseline, $73.4 \%$ maintained this condition at week 6 and $15.2 \%$ reported at least one criterion from Table 2. Among the 455 patients who had uncontrolled asthma at baseline, $54.7 \%$ achieved control of their asthma symptoms following the six-week study treatment regimen and $28.8 \%$ remained uncontrolled. Overall, at the six-week follow-up assessment, the proportion of patients with controlled asthma symptoms increased from $14.8 \%$ to $57.5 \%(\mathrm{P}<0.001)$. Among the 143 patients who remained uncontrolled after six weeks, $48 \%$ reported the presence of only one of the six asthma criteria listed in Table 2. Of the 79 patients with controlled asthma symptoms at baseline, 58 $(73.4 \%)$ maintained this condition at week 6, 12 (15.2\%) reported at least one of the six criteria and no data were available for nine (11.4\%). Similar improvements in asthma symptoms were observed for the 305 patients with AR (Tables 2 and 3).

For all patients, the mean $( \pm \mathrm{SD})$ ACQ score decreased from $1.44 \pm 0.82$ at baseline to $0.61 \pm 0.62$ at week 6 , representing an absolute mean change of $-0.82 \pm 0.85(\mathrm{P}<0.001)$ (Figure $1 \mathrm{~A})$. For the 143 patients $(26.8 \%)$ whose asthma symptoms were 


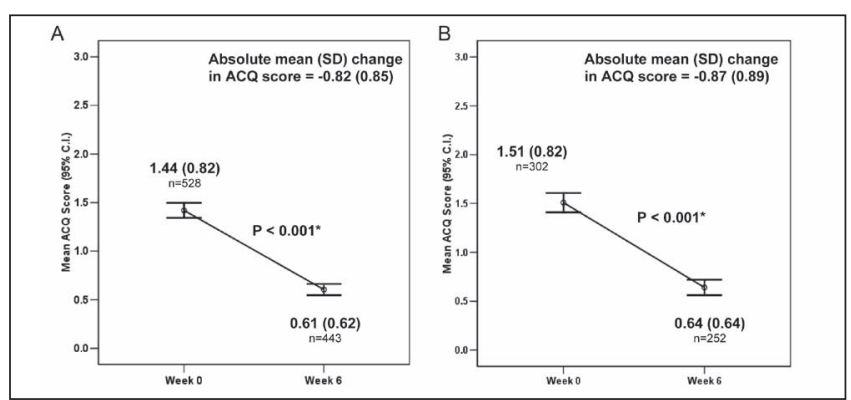

Figure 1) Mean (SD) Asthma Control Questionnaire (ACQ) score by visit. A For all patients; B For patients with concurrent allergic rhinitis

uncontrolled at the baseline and six-week assessments, the mean ACQ score decreased by $0.55 \pm 0.95(\mathrm{P}<0.001)$. A similar statistically significant $(\mathrm{P}<0.001)$ improvement in ACQ score was observed for the subgroup of patients with concurrent AR (Figure 1B).

The results of the 'investigator global satisfaction with treatment' question are summarized in Figure 2 and Table 4. At the baseline assessment, $56.6 \%$ of the treating physicians were dissatisfied with their patients' ICS treatment and 7.3\% were satisfied. At the six-week assessment, $8.4 \%$ of physicians were dissatisfied and $77.3 \%$ were satisfied with montelukast monotherapy. The changes in investigator satisfaction between the baseline and six-week assessments were statistically significant $(\mathrm{P}<0.001)$. The results of the 'patient global satisfaction with treatment' question were similar to those obtained for the 'physician satisfaction question' at both the baseline and six-week assessments. Similar changes in investigator and patient satisfaction with treatment were observed for the subgroup of patients with concurrent AR (Table 4).

\section{Compliance}

At baseline, there were 310 patients (58.1\%) who reported not missing any ICS doses during the previous two weeks, compared with 428 patients $(89.0 \%)$ who reported not having missed any montelukast doses during the six-week study treatment period $(\mathrm{P}<0.001)$. The proportion of patients taking $80 \%$ or more of their asthma medication increased from $49.4 \%$ at baseline to $87.7 \%$ at week $6(\mathrm{P}<0.001)$. Similar results with respect to treatment compliance were observed for the subgroup of patients with concurrent AR (data not shown).

\section{Safety}

A total of 40 treatment-emergent nonserious adverse events (NSAEs) were reported by 30 (5.6\%) of the 534 patients enrolled in the treatment phase of the study. Of these NSAEs, eight (20.0\%) led to treatment discontinuation and withdrawal from the study. The most frequent NSAEs reported that were related to the study treatment were nervous system disorders reported by 11 patients $(2.1 \%)$ (primarily headache, $\mathrm{n}=8,1.5 \%)$, followed by respiratory disorders reported by five patients $(0.9 \%)$ (asthma, $n=4$, $0.7 \%)$, and skin and subcutaneous disorders reported by five patients $(0.9 \%)$ (rash, $n=3,0.6 \%)$. There were no serious adverse events reported over the course of the study.

\section{DISCUSSION}

The goal of asthma care is asthma control. Poor asthma control has been associated with reduced quality of life, increased exacerbations and need for urgent care $(8,31)$. The results of the survey phase of the current study showed that an important proportion of patients with mild asthma do not achieve control of their asthma

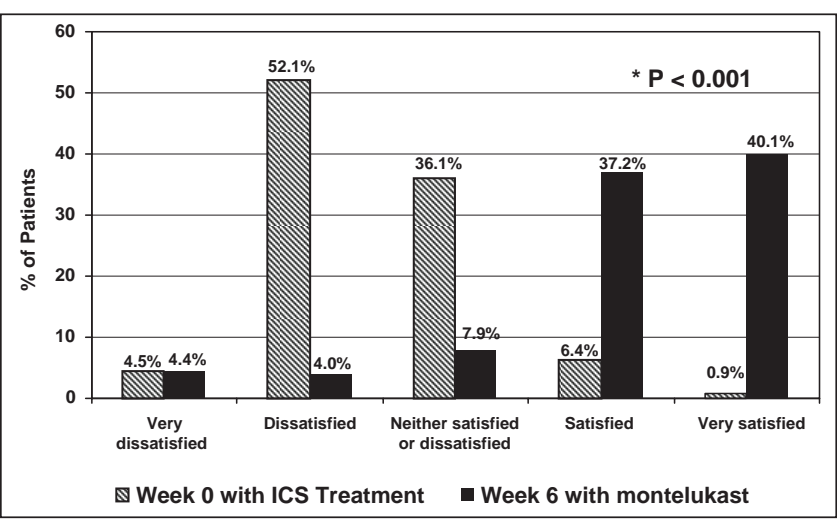

Figure 2) Investigator global satisfaction with inhaled corticosteroids (ICS) and montelukast treatment (all patients)

symptoms with ICS monotherapy. The survey phase showed a high rate of noncompliance with ICS treatment, which could partially explain the low level of therapeutic effectiveness observed with ICS monotherapy. Suboptimal compliance with ICSs may result from poor patient education with respect to the role of their asthma medications and their effective use, as well as concern for side effects $(9,10,21,32,33)$.

In the treatment phase of the present study, once-daily, orally administered montelukast monotherapy was effective in reducing asthma symptoms within six weeks of treatment onset. The majority of the patients achieved or maintained control of their asthma symptoms. In addition, decreases in ACQ score were not only statistically significant but were also clinically relevant; ACQ score decreases exceeding 0.5 have been validated to represent clinically significant improvements (28). An ACQ score higher than 1.5 is indicative of an $88 \%$ probability of uncontrolled asthma, and scores ranging between 0.75 and 1.5 are also indicative of not well-controlled asthma (29). Thus, although the mean ACQ score of the current patient population was below 1.5, this observation is in agreement with the current Canadian guidelines that were used to identify patients with uncontrolled asthma symptoms.

In the current study, the effectiveness of asthma symptom control was assessed using the ACQ, a widely used and validated instrument (28), and by evaluating the presence of specific and accepted asthma symptoms supported by the Canadian Asthma Consensus guidelines (27). These methods for assessing asthma effectiveness outcomes are considered suitable for the real-life clinical management of asthma because they are widely accessible and cost-effective methods (34).

Both physician and patient satisfaction with montelukast therapy were also significantly higher compared with baseline ICS treatment. The Global Asthma Physician and Patient (GAPP) Survey reported that, although $95 \%$ of physicians believed that ICSs were the 'gold standard' for asthma therapy, physicians were least satisfied with the side effects of ICS therapy compared with its other attributes. The survey also found that $81 \%$ of physicians believed that there were unmet needs in the area of ICS therapy (35).

Similar improvements in asthma symptom control and satisfaction with therapy were also observed in a subgroup of patients with concurrent AR. Improved symptom control in asthma patients with AR has also been previously reported with combined ICS and montelukast treatment $(24,36)$. Overall, these results are in agreement with those reported in the literature from controlled clinical trials and observational studies (25,37-41). 


\begin{tabular}{|c|c|c|c|c|c|c|}
\hline & \multicolumn{3}{|c|}{ All patients } & \multicolumn{3}{|c|}{ Concurrent AR patients } \\
\hline & $\begin{array}{l}\text { Baseline with ICS } \\
\text { treatment, } n=534\end{array}$ & $\begin{array}{l}\text { Week } 6 \text { with MON } \\
\text { treatment, } n=481\end{array}$ & $\mathbf{P}^{*}$ & $\begin{array}{l}\text { Baseline with ICS } \\
\text { treatment, } n=305\end{array}$ & $\begin{array}{l}\text { Week } 6 \text { with MON } \\
\text { treatment, } n=274\end{array}$ & $\mathbf{P}^{*}$ \\
\hline \multicolumn{7}{|c|}{ Investigator global satisfaction with treatment, n (\%) } \\
\hline Very dissatisfied & $24(4.5)$ & $21(4.4)$ & $<0.001$ & $14(4.6)$ & $14(5.1)$ & $<0.001$ \\
\hline Dissatisfied & $278(52.1)$ & $19(4.0)$ & & $163(53.4)$ & $11(4.0)$ & \\
\hline Neither satisfied or dissatisfied & $193(36.1)$ & $38(7.9)$ & & $111(36.4)$ & $28(10.2)$ & \\
\hline Satisfied & $34(6.4)$ & $179(37.2)$ & & $16(5.2)$ & $94(34.3)$ & \\
\hline Very satisfied & $5(0.9)$ & $193(40.1)$ & & $1(0.3)$ & $110(40.1)$ & \\
\hline \multicolumn{7}{|c|}{ Patient global satisfaction with treatment, $\mathbf{n}(\%)$} \\
\hline Very dissatisfied & $31(5.8)$ & $10(2.1)$ & $<0.001$ & $20(6.6)$ & $6(2.2)$ & $<0.001$ \\
\hline Dissatisfied & $189(35.4)$ & $17(3.5)$ & & $113(37.0)$ & $10(3.6)$ & \\
\hline Neither satisfied or dissatisfied & $183(34.2)$ & $55(11.4)$ & & $92(30.2)$ & $36(13.1)$ & \\
\hline Satisfied & $54(10.1)$ & $146(30.4)$ & & $30(9.8)$ & $87(31.8)$ & \\
\hline Very satisfied & $6(1.1)$ & $253(52.6)$ & & $4(1.3)$ & $134(48.9)$ & \\
\hline
\end{tabular}

*Based on the McNemar-Bowker test. AR Allergic rhinitis; ICS Inhaled corticosteroid; MON Montelukast

The results of the current study also demonstrated improved treatment compliance with montelukast therapy compared with prior ICS therapy. However, improved compliance with montelukast compared with ICS therapy may be due primarily to its oral administration, which is more user friendly than ICS inhalation, and second, to its once-daily dosing regimen. Several studies have shown that patient adherence to asthma medication is influenced by the mode of delivery and the dosing frequency $(20,42,43)$. Availability of the treatment free of charge and participation in a clinical study may also result in overestimation of the true compliance in real life, in which access to treatment and reduced physician contact may reduce adherence.

Overall, montelukast once daily was well tolerated and safe during the six-week treatment period of the study. The adverse events that occurred generally resolved with no residual effects, and no serious adverse events occurred.

The potential limitations of the current study are related to the open-label and single-cohort design. However, the open-label design is necessary because blinding with respect to the treatment is not compatible with emulation of the real-life setting and routine clinical practice. It is important to supplement the evidence generated in controlled clinical trials with open-label effectiveness postmarketing studies, and to integrate findings from these studies into guidelines and educational initiatives. Furthermore, although the lack of a control group may not allow for parallel or direct comparison with other treatments, the intent of the study was not to compare montelukast with alternative therapies, but to assess the effectiveness of montelukast in the management of patients with mild asthma who had not achieved a satisfactory therapeutic response with previous ICS monotherapy. Therefore, the baseline state, representing the effect of previous treatment, should be considered the control against which the new treatment is evaluated. An additional limitation of the current study was the possibility for selection bias in the sample population, because patients who were selected by their treating physician may have been more likely to be compliant and to complete the study. However, this is unlikely, given that less than $60 \%$ of the patients had been compliant with their baseline ICS therapy. Additionally, there may be concern that the selected patients may have been more likely to respond to montelukast treatment. However, there is no way of knowing who would respond to this therapy and, in real-life practice, physicians switch treatment if patients are not responding or adhering to their existing therapy. Lastly, there may be ethical concerns that arise when treatment is stopped and switched in patients whose asthma symptoms are well controlled. However, the aim of this observational study was to emulate the real-life setting in which patients who are not satisfied with treatment, despite being controlled, may not be compliant or may terminate their treatment. In fact, in the current study, patients with controlled symptoms were only admissible if change in treatment was considered or indicated by the treating physician.

The strengths of the current study include the selection of a cross-section of both urban and rural physician-investigators and patients across Canada, thus allowing generalization of the results to the target population.

A major care gap in asthma management is the application of guideline-defined therapy in office practice. It is difficult to truly reflect day-to-day care once one starts to evaluate patients in any clinical trial. In this phase IV study, patients were selected and treated in accordance to a predefined protocol. The use of a predefined protocol may not be compatible with the strict definition of an observational study conducted in a real-life setting. However, emulation of the real-life setting and routine clinical practice was attempted using a protocol that was established as per the product monograph adhering to current treatment guidelines, less stringent inclusion and exclusion criteria, allowing the use of rescue medication and including all treated patients in the analysis. In addition, the study used a prospective cohort design that precluded recall bias. The use of standardized self-administered questionnaires reduced potential ascertainment bias.

\section{CONCLUSIONS}

The results of this open-label, phase IV study show that once-daily montelukast therapy is effective and well tolerated in patients with mild asthma who were previously uncontrolled or dissatisfied when treated with low-dose ICS.

FUNDING: This study was funded by Merck Frosst Ltd.

ACKNOWLEDGEMENTS: Financial disclosures and potential conflicts of interest: C Koch is a former employee in Clinical Research at Merck Frosst Canada Ltd; J Sampalis is an employee of JSS Medical Research Inc (CRO); RA McIvor and A Kaplan are consultants for the SIMPLE study. Dr McIvor has received honoraria for CME and attending advisory board meetings for Abbott, AstraZeneca, Boehringer Ingelheim, GlaxoSmithKline, Merck Frosst, Novartis, Nycomed and Pfizer. Dr Kaplan has received honoraria for CME and attending Advisory Board meetings for Abbot, AstraZeneca, Boehringer Ingelheim, Jansen Ortho, Merck Frosst, Nycomed, Pfizer and Purdue. All investigators received grants related to the conduct of the study including but not limited to patient recruitment and case report form completion on a pro-rated basis. List of 
investigators: British Columbia: Ableman, Darryl; Alisharan, Robert; Horner, Richard; Hosie, Andrew; Kiellerman, Eva; Lowe, Derek; Lubbe, Gerald W; Marais, Cilliers; Richards, Peter; Singhal, Manoj; Ukpeh, Henry Asuquo; White, Diana Mary; White, J Patrick; Alberta: Goldade, Roxanne; Ollewagen, Ferdinand; Saskatchewan: Achyuthan, Geeta; Arndt, Susanne; Datta, Biswa; Krochak, Carla; Nayar, Arun; Yuen, Vincent; Manitoba: Bedder, Phyllis; Horne, David; Kroczak, Tadeusz; Winogrodzka, Christina; Ontario: Albus, Wayne; Awuku, Mark; Barnard, Thomas; Bhatt, Gunvant; Buttoo, Ajit; Chan, David Yiu Kin; Chaudhri, Arif; Chawla, Harvinder; Che, Claudius; Chung, Chin Kwan; Chung, Pin; Climpson-Kennedy, Lauretta Gayle; Csanadi, Michael; Despard, Caroline; Donkor, LW Kwane; Garfield, Hartley; Grad, Elliott; Gurwitz, E Dennis; Jones, Michael; Joshi, Shel; Kalra, Bharat; Kaplan, Alan; Khattak, Sohail; Kumar, Vijay; Langer, Howard; Leung Sui Fung, Max; Luton, Robert; Mah, Douglas; Mawji, Al; Milne, Janette; Mohammed, Afzal; Morana, Corrado; Morgan, Susan; Ng, Albert; Nguyen, Phuongbich; Nunes-Vaz, Claire M; O’Mahony, William F; Obaji, Hind I; Paikatt, Santosh; Pavri, Daisy; Petrlich, Steve; Pinto, Barbara; Ramji, Shaffiq; Rogan, George; Rose, Roger; Ruggiero, Donato Anthony; Russell, Alan; Sabry, Boshra; Shiraz, Ismail; Singh, Kunwar; Toledano, Daniel R; Vandenberg, Alison Patricia; Wong, Albert See Chee; Yellin, Joel; Yu, Norman; Quebec: Barriere, Ginette; Belle-Isle, Jasmin; De Repentigny, Gaetan; Desroches, Jacques; Dumais, Michelle; Gonzalez, Yolanda; Goyer, Pierre; Guite, Christian; Hejazi, Banafcheh; Houde, Danielle; Lamarre, Caroline; Leduc, Christian; Lindor, Marie-Helene; Ludovic, Plante Jr; Mazza, Giuseppe; Meunier, Pierre; Nguyen, Gia Khanh; Normandin, Diane; Payer, Pierre; Roberge, Claude; Soowamber, Mohunlall; Theriault, Lyne; Tran, Tri-Minh; Vu, The-Hung; New Brunswick: Anand, Sanjiu; Harper, William; Lamontagne, Rene; Nova Scotia: Azer, Raed; Brown, Charles; Bustin, Robin; Gallant, Steven Joseph; Kirkpatrick, John H; Shimon, Laith Dinkha; Newfoundland: Greene, Mabel; King, Susan; McGrath, Sheilagh.

\section{REFERENCES}

1. Global Strategy for Asthma Management and Prevention. Global Initiative for Asthma (GINA), 2006. <www ginasthma org > (Version current at 2006)

2. Camargos PA, Rodrigues ME, Sole D, Scheinmann P. Asthma and allergic rhinitis as symptoms of the same disease: A paradigm under construction. J Pediatr (Rio J) 2002;78(Suppl 2):S123-8.

3. Leynaert B, Bousquet J, Neukirch C, Liard R, Neukirch F. Perennial rhinitis: An independent risk factor for asthma in nonatopic subjects: Results from the European Community Respiratory Health Survey. J Allergy Clin Immunol 1999; 104:301-4

4. Sibbald B, Rink E. Epidemiology of seasonal and perennial rhinitis: Clinical presentation and medical history. Thorax 1991;46:895-901.

5. Price D, Zhang Q, Kocevar VS, Yin DD, Thomas M. Effect of a concomitant diagnosis of allergic rhinitis on asthma-related health care use by adults. Clin Exp Allergy 2005;35:282-7.

6. Bousquet J, Gaugris S, Kocevar VS, et al. Increased risk of asthma attacks and emergency visits among asthma patients with allergic rhinitis: A subgroup analysis of the improving asthma control trial. Clin Exp Allergy 2005;35:723-7.

7. Mintz M. Asthma update: Part II. Medical management. Am Fam Physician 2004;70:1061-6

8. National Asthma Education and Prevention Program: Expert Panel Report: Guidelines for the diagnosis and management of asthma. Update on Selected Topics - 2002. J Allergy Clin Immunol 2002;110(Suppl 1):S141-219.

9. Cowie RL, Underwood MF, Field SK. Inhaled corticosteroid therapy does not control asthma. Can Respir J 2004;11:555-8.

10. Chapman KR, Ernst P, Grenville A, Dewland P, Zimmerman S. Control of asthma in Canada: Failure to achieve guideline targets. Can Respir J 2001;8(Suppl A):35A-40A.

11. Lazarus SC, Chinchilli VM, Rollings NJ, et al. Smoking affects response to inhaled corticosteroids or leukotriene receptor antagonists in asthma. Am J Respir Crit Care Med 2007;175:783-90.

12. Clark N, Jones P, Keller S, Vermeire P. Patient factors and compliance with asthma therapy. Respir Med 1999;93:856-62.

13. Cochrane MG, Bala MV, Downs KE, Mauskopf J, Ben-Joseph RH. Inhaled corticosteroids for asthma therapy: Patient compliance, devices, and inhalation technique. Chest 2000;117:542-50.

14. Haynes RB, McDonald H, Garg AX, Montague P. Interventions for helping patients follow prescriptions for medications. Cochrane Database Syst Rev 2002;(2):CD000011.

15. Biernacki W, Kharitonov SA, Biernacka HM, Barnes PJ. Effect of montelukast on exhaled leukotrienes and quality of life in asthmatic patients. Chest 2005;128:1958-63.
16. Apter A, Reisin S, Affleck G, Barrows E, ZuWallack R. Adherence with twice-daily dosing of inhaled steroids. Am J Respir Crit Care Med 1998; 157:1817.

17. Jonasson G, Carlsen K-H, Mowinckel P. Patient compliance in a clinical trial with inhaled budesonide in children with mild asthma. Eur Respir J $1999 ; 14: 150-4$.

18. Gunnar J, Carlsen K-H, Mowinckel P. Asthma drug adherence in a long-term clinical trial. Arch Dis Child 2000;83:330-3

19. Milgrom H, Bender B, Ackerson L, Bowry P, Smith B, Rand C. Noncompliance and treatment failure in children with asthma. J Allergy Clin Immunol 1996;98:1051-7.

20. Stempel DA, Stoloff SW, Carranza Rosenzweig JR, Stanford RH, Ryskina KL, Legorreta AP. Adherence to asthma controller medication regimens. Respir Med 2005;99:1263-7.

21. McIvor RA, Boulet LP, Fitzgerald D, Zimmerman S, Chapman KR. Asthma control in Canada. No improvement since we last looked in 1999. Can Fam Physician 2007;53:672-7

22. FitzGerald JM, Boulet LP, McIvor RA, Zimmerman S, Chapman KR. Asthma control in Canada remains suboptimal: The Reality of Asthma Control (TRAC) study. Can Respir J 2006;13:253-9

23. Malmstrom K, Rodriguez-Gomez G, Guerra J, et al. Oral montelukast, inhaled beclomethasone, and placebo for chronic asthma. A randomized, controlled trial. Montelukast/Beclomethasone Study Group. Ann Intern Med 1999; 130:487-95.

24. Price DB, Swern A, Tozzi CA, Philip G, Polos P. Effect of montelukast on lung function in asthma patients with allergic rhinitis: Analysis from the COMPACT trial. Allergy 2006;61:737-42.

25. Virchow JC, Bachert C. Efficacy and safety of montelukast in adults with asthma and allergic rhinitis. Respir Med 2006;100:1952-9.

26. Philip G, Nayak AS, Berger WE, et al. The effect of montelukast on rhinitis symptoms in patients with asthma and seasonal allergic rhinitis. Curr Med Res Opin 2004;20:1549-58.

27. Becker A, Lemiere C, Berube D, et al. Summary of recommendations from the Canadian Asthma Consensus guidelines, 2003. CMAJ 2005;173(6 Suppl):S3-11.

28. Juniper EF, O'Byrne PM, Guyatt GH, Ferrie PJ, King DR. Development and validation of a questionnaire to measure asthma control. Eur Respir J 1999;14:902-7.

29. Juniper EF, Bousquet J, Abetz L, Bateman ED. Identifying 'well-controlled' and 'not well-controlled' asthma using the Asthma Control Questionnaire. Respir Med 2006;100:616-21

30. International Conference on Harmonization of Technical Requirements for Registration of Pharmaceuticals for Human Use (ICH). Medical Dictionary for Regulatory Activities Terminology (MedDRA Version 9.0). 2006 .

31. Braman S. The global burden of asthma. Chest 2006;130:4-12.

32. Boulet LP. Perception of the role and potential side effects of inhaled corticosteroids among asthmatic patients. Chest 1998;113:587-92.

33. Rossi GA, Cerasoli F, Cazzola M. Safety of inhaled corticosteroids: Room for improvement. Pulm Pharmacol Ther 2007;20:23-35.

34. van den Nieuwenhof L, Schermer T, Eysingk P, et al. Can the asthma control questionnaire be used to differentiate between patients with controlled and uncontrolled asthma symptoms? A pilot study. Fam Pract 2006;23:674-81.

35. Canonica GW, Baena-Cagnani CE, Blaiss MS, Dahl R, Kaliner MA, Valovirta EJ. Unmet needs in asthma: Global Asthma Physician and Patient (GAPP) Survey: Global adult findings. Allergy 2007;62:668-74.

36. Zhang Q, Thomas M, Wisniewski T, Sazonov Kocevar V, Price D. Treatment and outcomes in patients with asthma and allergic rhinitis in the United Kingdom. Int Arch Allergy Immunol 2007;142:318-28.

37. Ghosh G, Manglik AK, Roy S. Efficacy and safety of montelukast as monotherapy in children with mild persistent asthma. Indian Pediatr 2006; 43:780-5.

38. Reiss TF, Chervinsky P, Dockhorn RJ, Shingo S, Seidenberg B, Edwards TB. Montelukast, a once-daily leukotriene receptor antagonist, in the treatment of chronic asthma: A multicenter, randomized, double-blind trial. Montelukast Clinical Research Study Group. Arch Intern Med 1998;158:1213-20.

39. Barnes N, Thomas M, Price D, Tate H. The national montelukast survey. J Allergy Clin Immunol 2005;115:47-54.

40. Knorr B, Matz J, Bernstein JA, et al. Montelukast for chronic asthma in 6- to 14-year-old children: A randomized, double-blind trial. Pediatric Montelukast Study Group. JAMA 1998;279:1181-6.

41. Narayanan S, Edelman JM, Berger ML, Markson LE. Asthma control and patient satisfaction among early pediatric users of montelukast. J Asthma 2002;39:757.

42. Carter E, Ananthakrishnan M. Adherence to montelukast versus inhaled corticosteroids in children with asthma. Pediatr Pulmonol 2003;36:301-4.

43. Rand C, Bilderback A, Schiller K, Edelman JM, Hustad CM,

Zeiger RS. Adherence with montelukast or fluticasone in a long-term clinical trial: results from the mild asthma montelukast versus inhaled corticosteroid trial. J Allergy Clin Immunol 2007;119:916-23. 


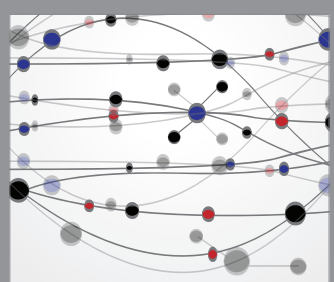

The Scientific World Journal
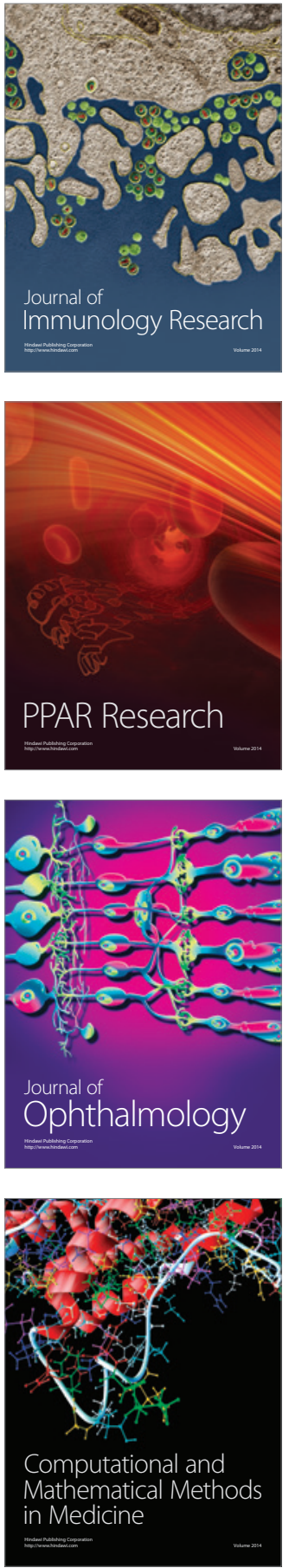

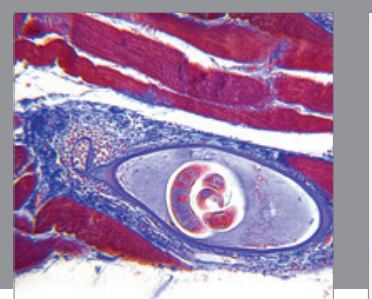

Gastroenterology Research and Practice

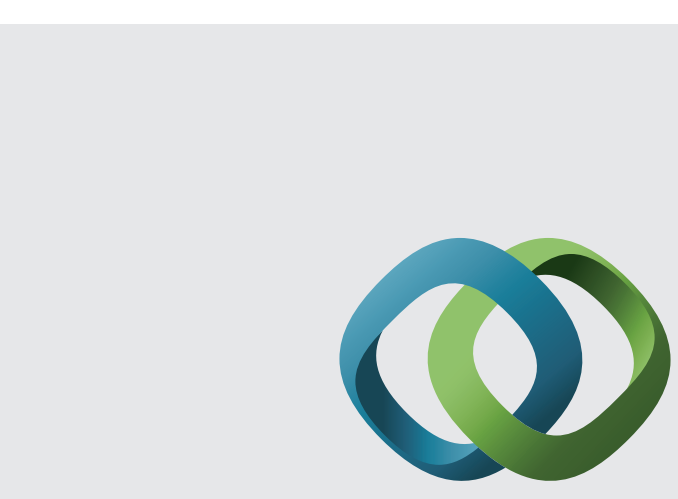

\section{Hindawi}

Submit your manuscripts at

http://www.hindawi.com
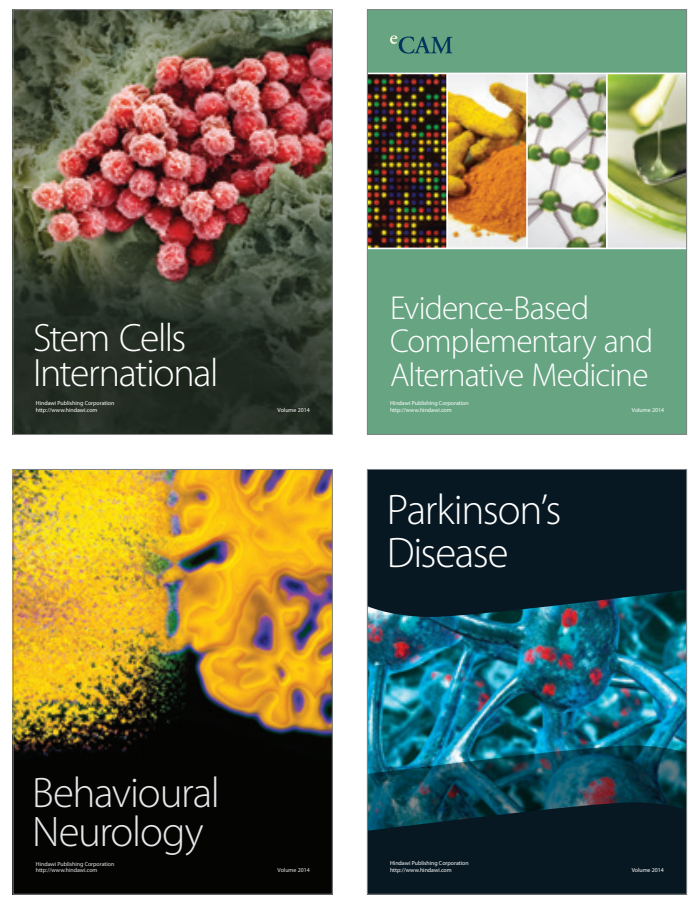
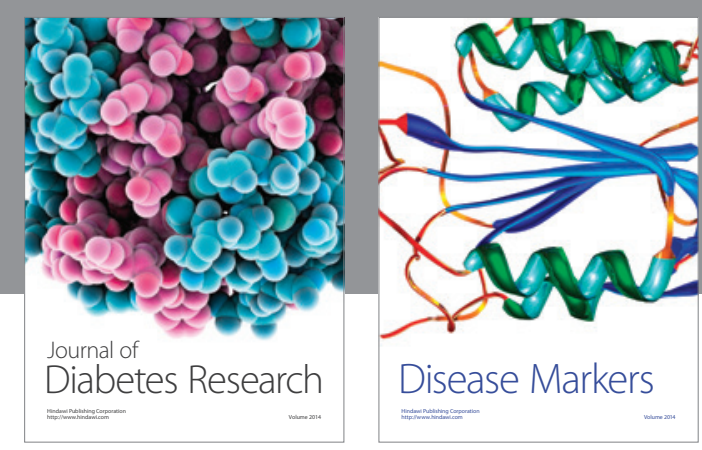

Disease Markers
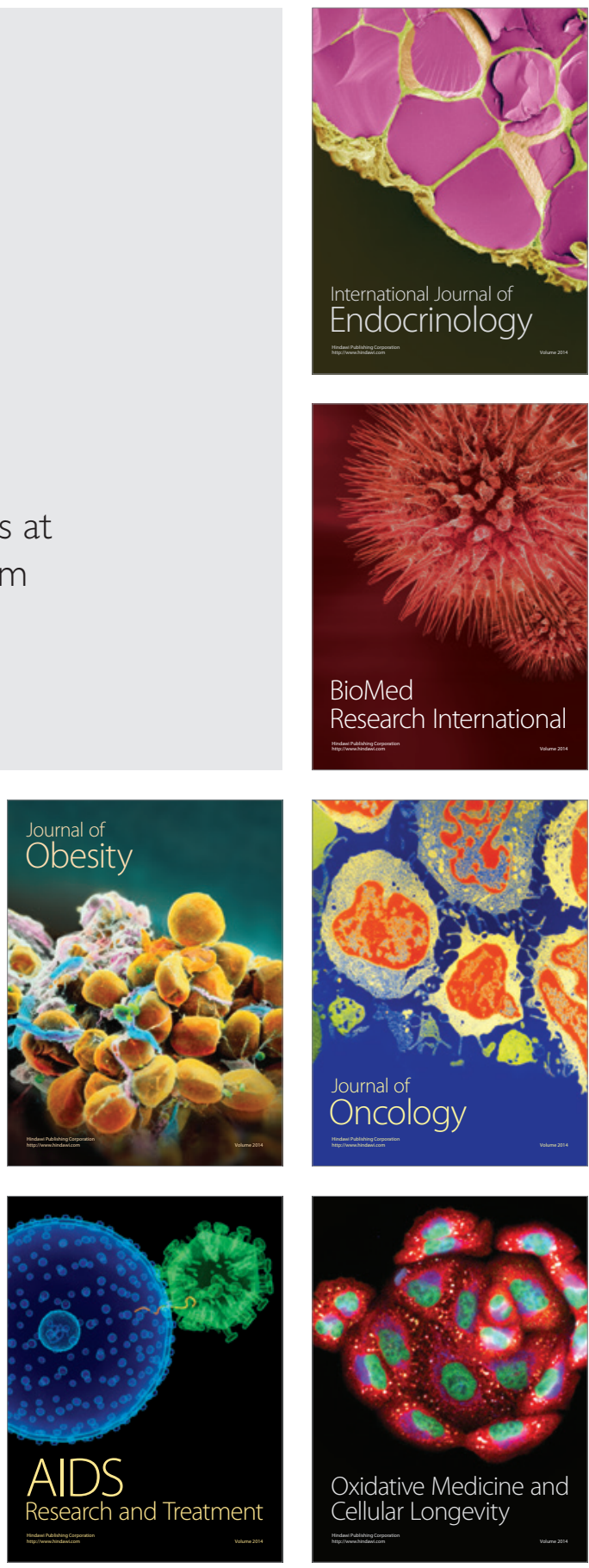